\section{(Clintiral Perture} on

\section{SOME TYPES OF CONJUNCTIVITIS.}

Deliverhd at the Ulster Hospital, Belfast.

Bу H. H. B. CUNNINGHAM, M.D., F.R.C.S.I., M R.C.S.ENG,

OPHTHAIMIC SURGEON, ULSTER HOSPITAL FOR CHICDREN AND WOMEN, BELFAST ; LATK CHIEF CLINICAL ASSISTANTT, ROYAL LONDON OPHTHALMIC HOSPITAL.

\section{INTRODUCTORY.}

The conjunctiva, the mucous membrane lining the inner surfaces of the eyelids, whence it is reflected on to the globe of the eye, of which it covers the anterior third, may be deseribed as consisting of three portions, the palpebral, the fornices, and the ocular; the Jatter may be subdivided into scleral and corneal. The palpebral conjunctiva lines the inner surfaces of both upper and lower lids, at the edges of which it is gradually transformed into the epithelium of the skin: it is closely attached to the tarsal plates, and thence passes into the fornices, where it is reflected from the lids on to the eyeball ; they consist of some small folds placed parallel to the length of the lids: this arrangement allows the $\epsilon \mathrm{ye}$ to move freely in a'l directions, irrespective to a great extent of the lids. The scleral portion extends from the fornices to the limbus, whence it passes into the corneal conjunctiva; it is very loosely attached to the subjacent sclera, and on the cornea the membrane resolves itself in the anterior epithelium of that structure. Near the caruncle is a fold of the membrane, the plica semilunaris, which corresponds to the membrana nictitans: prement in birds and many quadrapeds. Histologically the conjunctiva consists of two portions, the epithelium and the substantia propria. The character of the; epithelium varies in different positions, the palpebral portion consists of a laminated cylindrical type in two layers, of which the cylindrical cells are superficial; at the fornices three layers are found, and in the scleral-portion the epithelium is gradually becoming stratified, belng definitely so at the limbus. Acinous mucous glands (Waldeyer's glands) are found along the convex border of the tarsal, plates, analogous glands (Krause's glands) in the fornices. Goblet cells are found in all parts of the conjunctival epithelium, but especially in the fornices and scleral portions; their presence is of the utmost importance, for it is due to their secretlon moistening and so protecting the conjunctiva and cornea that we are enabled to remove the lacrymal gland without any ill effects.. The substantia propria is of an adenoid type-that is, it consists of fibrous connective tissue contalning many lymphocytes, especially in its superficial layers; it is this fibrous layer which is closely connected to the tarsal plates, and into it the posterior lamella of the levator palpebrae superioris is inserted. The blood supply is derived from the palpebral and from the anterior ciliary arteries.

Páthotogr of 'Conjunctivitis.

As in all forms of inflammation there is a dilatation of the lymphatics and of the conjunctival blood vessels, with exudation of serum and diapedesis, lencocytes, lympho. cytes, and plasma cells are found in abundance, the lymphocytes normally present in the substantia propris of the conjunctlva are largely increased in numbers; this structure being of loose connective tissue is 'easily distended with exudation, thus causing the chemosis so frequently seen. The epithelium itself is swollen, thus accounting for the loss of transparency so often noticed; the goblet cells are increased in numbers, especially in the chronic types of inflammation; indeed, new tubular glands are even formed. The secretion exuded varies in consistence, from the aqueous fluid seen in ephiphora resulting from a reflex stimulation of the lacrymal gland t) thick muco pus or even pus; this discharge contains, in addition to the lacrymal secretion, plasma exuded from the blood vessels, mucus from the goblet cells and acinous glands, and a varying number of leucocytes and pas corpuscles.

Crassibication.

As I only intend to discuss a few types of conjunctlvitis to day, I will not attempt a classification of the various forms of this disease.
Catarrhal Conjunctivitis.

Catarrhal conjunctivitis may be divided Into.acute and chronic. The causes of the acute variety may be divided into predisposing and exciting. The former consist in the main of a lowering either of the local vitality, as by a cold or presence of a foreign body, or of the general vitality, from defective hygienic surroundings, and insufficient or unwholesome food, this latter cause being met principally in the class of patients who come to hospital for treatment. The exciting causes are several microorganisms, of which the bacillus discovered by Koch in Egypt in 1884 and by Weelrs in New York in 1885 is by far the most common. This bacillus, usually called the Koch-Weeks bacillus, is a short fine rod, which is difficult to grow in culture; it is non-motile, stains faintly with aniline dyes, and is decolorized by Gram's method. The bacillus attacks all ages, bat most frequently the young; it causes a muco-purulent conjunctivitis which is highly contagious. Handkerchiefs, towels, etc., are the usual media of contagion, and when one member of a household is attacked by this disease, usually every other member is subsequently affected. It 1s this disease which sometimes breaks out in schools, and is then known as school ophthalmia. The pneumococcus also gives rise to epidemics, usually among the young. Gelpke described a form of the kerosis bacillus as the Bacillus septatus in an epidemic of this disease. Among other micro-organisms found streptococci may be mentioned; a pure culture is seldom obtalned, and in those cases in which it is found the prognosis is usually not good, as in the following instance:

A. F., aged 2, was brought to hospital with a history of the left eye having been sore and inflamed for the previous three weeks, subsequent to the appearance of $\mathrm{s}$ dry eruption on his weeks, subsequent to the appearance of a dry eruption on his their eyes recently; there was no family history of syphilis or their eyes recently ; there was no family history of syphilis or
of tubercle. There was slight oedems of the leit eyellds, and some glueing of the lids in the mornings; there : Wis : 8 large swelling in the region of the left parotid gland; whieh had lasted for three weeks, and : a number of enlarged lymphatic glands in the posterior triangles of the neck; there were no pediculi. He was treated on the lines to be indicated presently. Three days later there was chemosils, marked oedems of the lids, muco-purulent discharge, and the eriution on the face had become puralent in places. Four dayslister the tace had become purulent in places. Four daysiater the enlarged glands were, in a similar condition, the eruption on his face was less and cleaner, the oedema of the lids.Was a had increased, the muco-puralent discharge was increased and free, there was a hypopyon half filling the anterior chambar, the cornea was cloudy and contained a large central septic ulcer, and, in 'short', the eye was lost. The puis taken from thls case gave a nearly pure culture of streptocoeoi.

The symptoms of this condition vary in severity; a history is usually given that the sufferer caught a cold in the eye, or canght it from another child, both eyes belng affected at once, or one shortly after the other; the child complains of more or lesis photophobia and burning of the lids; there is some epiphord, and the sight may: be dimmed by shreds of mucias floating on to the cornea; the lids may be stuck together in the morning with tears and muco-pus pent up inside.' 'The lids are sómetimes oedematous, the ocular conjunctiva is injected, hence the name "pink eye." Chemosis is freguentt; and on everting the lids the palpebral conjuninctiva is seen to be markedly injected, flakes of muco-pus flaating about in the tears; the quantity of this and the amount of injection vary with the severity of the inflammation; this condition may be complicated by the presence of corneal ulcers or iritis; as in the following case :

M. M., aged 8 months, was brought to hospital with the usual symptoms detalled above, which had commenced a week prevlously ; ordinary treatment was adopted; four dáys later the child was better and could open her eyes a little herself, though the edges of the lids were sore. The child was not seen for six days, when there was an exscerbation of the disease in the right eye, and in addition in the left there was disease in the right eye, and in addition in the left there was diffase suppurative keratitis, with a central septic ulcer.
Again, she was not brought back for ten days, when the conAgain, she was not brought back for ten days, when the con-
dition was very similar. Four days later she was better, the dition was very similar. Four days later she was better, the
ulcer had healed, and she could open her eye herself a little; three days later sho was almost well.

This condition usually lasts for a week or a lortnight, but cases are frequently met, with in which there is definite rhinorrhoea.

A. C., aged 3, was brocght to hospital with a history of sore eyes for the-previous three weeks ' he hád "mild symptoms of the complaint, coupled with double otorrhoeg, and with [2447] 
rhinorrhoea. He was seen regularly, and the condition slowly improved. Three weeks later the rhinorrhoea and otorrhoe both cessed, and he could open his eyes slightly. A fortnight later, he had no photophobia, could open hls eyes easily himlater, he had no photopho

The treatment of thils complaint is simple. I am in the habit of ordering for use at home boracic lotion to bathe the eyes frequently, with the application of boracic ointment to the inner sides of the lids night and morning, and of performing myself what Darier calls "savonnage"that is, brushing the overted lids with either argyrol or protargol ouce a day orless frequently, according to the severity of the symptoms; some surgeons use a solution of silver nitrate, but I reserve this powerful caustic for those cases which will not react to the above treatment. The following cases illustrate the result of treatment of this condition

安,8, aged 10, was brought to hospital complsining of sore ejas for a week; both palpebral and ocular conjunctives were Ififl tmed, and muco-pus was flagiting in the sac; she was ordered boracic lotion and ointment for home use, and savonnage was performed'; her attendahco was very irregular, still the s $3 \mathrm{~m}$ trea ment was continued orid in five weeks she was quito well.

8. B., aged 12, was brought to hospital with \& history of bring had sore cos for tive weeks. The conjunctiva was injected, the cornese clear, and muco-pus was present in the sacs; there was also photophobia. He was ordered boracic sacs; there was siso photophobia. He was ordered boracic lotion for home use, and the lids were painted with argyrol ; well in three weeks.

Chronic catarxhal conjunctivitis may result from a preceding acute attack which has not resolved, or from the irritation of a foreign body; it is frequently seen in bullarencaling from an attack of measles:; in adults it is diften seen in patients whose occupation exposes their ases to constant irritation by injurious gases, particles of dust smoke, etc.; in the aged it is frequent. Darier ${ }^{2}$ mentionstan alcoholio tope. In whatever manner started, the most Irequent cause of the continuation of this compaldint is an error of refraction, especially astigmatism. Witsibus bactexis are faund in the conjunctivil sac, but there is one form of nicro-organism, the bacillus discovered independently by Morax and by Axenfeld in. 1896, 2 diplobacillus decolorized by Gram's method and difficalt to grow in culture, which gives aise to a definite type of chronio conjunctivitis, known sometimes as "chronic angular conjunctivitis." the sthjective symptoms of this affection are very definite : an aching of the eyes, a feeling of heaviness in the lids and of send: in the eyes, which becomes more menked towtrds evening; the lids are glued together in the morriftig, and the patient will ses that he has to bathe the in ordes to apen the lids. Objectively there is Hor welling of the corijunctivar, the fornices and palpebral conjunctiva ere injectsed there is, it angthing, diminished secretion. In angular conjunctivitis the edges: of the tarsal plates are injected. This condition does not, as a wulle, resolve opontaneously, but goes on to involve the edges rof the lids; causing loss of the cilis and in elderly people it will cause eczema of the skin of the lower lid which In'sts turn will set up ectropion. The treatment may be divited into general and local. In the first place, wo must remove the patient into better hygienic surrounditim ar protect his eyes by means of goggles from the effeots ofldnst, etc., and prescribe suitable glasses for any error of mefraction; locally, an astringent lotion suoh as altw itannin; or zino sulphate, is used to bsthe the ezes, wndsinglevintment is'placed inside the lids night and morning. The following case is a typical example:

$L_{i} B_{k}$, aged $25_{3}$ comesto hospital complaining of sore ejes of wo months aturation. She had suffered from sore eyes on and off for sores prears; there was alwags more or less blepharttis, the byeleshes were defivient, especialls in the hower lids; bud there was a lencome adherens in the leftreje, whibh was' amblyapie; there was constunt unilateral convergen strabismus, with an angle of about 20 degrees, the right eyotholitg the fixingieye. The conjunotivitis in thorlght reye was oomplica bed by a fresh ulcor on the cornes. Atropine was instillea inito theright with borkist lotion, end boracio olntment smeared on the edges of the lids. In three weeks the alcer had quite healed, and the blepharo-conjunctivitis was distinctly less. A month laber, 'as'thre conjundthitis was

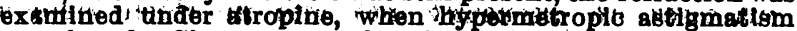
was found. Glasses were therefore ordered, an $d^{\prime}$ stx Iater the inflemmationarwas considerably reduced. A mercurial

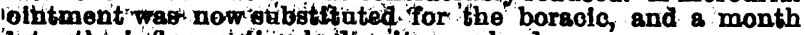
Ister the inflammbefion hadiquilto resolved.
Phlyctenular Conjunctivitis.

Phlyctenular ophthalmia, also chled comstous conjunctivitis or lymphatic conjuntetivitis, is a condition occasionally seen in adults, but most frequently in the children of the artisan class, most of them either definiteby tuberculous or showing the so.called strumous diathesis, but in those cases at this hospital in which the opsonic index for tubercle was taken it was found to be normal. Many of these children suffer from tuberculous glands in the neck, and there is frequently a family history of consumption. Coming to the individual case, we ususily flid that the child spends most of her time indoors, sleeps in a room with several others, ventilation at night is not approved of, and frequently she and soap and water are not on the best of terms. The food these chilaren get is not always the most nourlshing; they drink quantities of tea but very little milk, and fat in its various forms they egchew. No definite bacillus has yet been indicated as the carise of phlyctenular ophthalmia, though several have been found. The phlyctenule appears as a small elevation on the limbus conjunctivae usually; and consists of a round-celled infiltration situated immécifately beneath the epithelium, which is raised over itt and thinned; the invading cells consist of uninuclear and multinuclear leucocytes, small at the periphery but increasing in size towards the centre of the nodule; giant cells have been found by Leber ${ }^{3}$ and Wintersteiner. It thus commences as a solid nodule, from which the surface epithelium and part of the nodule, having undergone necrosis, are cast off, thus forming a superficial ulcer. Von Michel, ${ }^{4}$ however, states that vesicles and even pustukes are actually formed, and the ulcer results from necrosis of their outer wall. The actual cause of the philyctaena is thought to be the reaction of that part of the tisene to sthe toxinglof the tubercle bacillus, and it is ascrirbed to th endogenotis, as opposed to an ectogenous, origin. The symptoms vary in severity considerably; stibjectively there is photophobia frequently very marked, as in case L. J. mentioned below, where there was so much blepherospasm that it was with the atimost diffoulty i was able to examine the condition of her eyes, Lacrymation may be more or less profuse; but there is no muco-purulent secretion, as a rule, so the lids do not stick together in the "morting"; ustally the child keeps her hand or a handkerchief 'over her eves, stips at home and remains indoors, and preferably in a daik corner. Objectively'a smbn red projection is seen on the limbus conjunctivae surrounded by a zone of injected conjunctival vessels, occasionally a yellowlsh point can be seen in the centre of the red projection; the nodule' mas be a few millimetres away from the limbus; or it may'be actually on the cornea. Instead of one philyctaena there may be several minute ones (milliary fhlydetenulae) around the eage of the comea, of several ratiger ones on the limbuts. These elevations break down atit form ulcers, whlch usually heal in the course of a week or two, the patch of conjunctivitis resolving at the sme time, and the epithillum growing over the ulcer, no trace of it is left. But this is followed by a subsectuentattack, perhaps before the previous one has quite cleared ap, or shortly after. These attacks rectur for some years, sometlmes till adult age, thus making the disease trying to the patient and practitioner alike. In more severe forms, where there are several phlyctaenae on the conjunctiva or on the cormea, each attack is much prolonged, and is much more difficult to treat. The case of $L$. J. is an example. She has been under constant treatment for some mbnths, both as an in-patient and as an out-patient, and though much improved she is not quite well. The cornesl complichtions I do not intend to discuss to-day.

The treatment of this condition must be general as well as local, therefore one advises the child to be out of doors all day; in a severe case one prescribes dark glasses, to counteract the photophobia, plain, wholesome food, plenty of milk and fat in some form or other, and the admitinis. tration. of cod-liver oil, locally frequent irrigation of the eye with warm boracic lotion, and the afplication of Fellow oxide of mercury ointment. If the case is severe it is ibetter to content oneself with boracic olntment at first tin the severity of the attack thas ofiminished a little. These messures are usually quite sufficient to bribg abbut a cure. If the cornes is involved, atropine must be instilled in adđation.

M. C., aged 13, came complaining of sorereges on and off. for 
Che past two years, in spite of treatment: Six jears ago the eyes were similarly affeoted. The present attack has lasted for a month; the child keeps, indoors all day; there is marked conjunctivitis and photophobla, but no rhinorrhoea. There is no family history af tabercle, but of ten stillborn children. The ejes showed large phlyctenulae she was treated in the The ejes showed large phlyctenulae, She was treated
usual way, and recovery was complete in a few days.

asual way, and recovery was complete in a few days.
A. C. came with all the symptoms of a severe chronic catarrhal copjunctivitis, complicated by: the presence, of septic ulcer on the left cornea. She gave a history of sore eyes for the previous year, but they had probably been in this condition for a longer period, as most of the cilia were missing, and some of those present were distorted. She was treated with boracic lotion, atropine, and fomentations, with the result that in three weeks the ulcer was healed and the conjunctivitis much lessened, bat then some phlyctenular ulcers were seen on the outer side of the limbus of the left eye, thus showing the nature of the previous ulcer. A week later these ulcers, three in number, were markedly raised up from the surface of the conjunctiva and gave the apparance of tubercles rather than phlyctenulae. The treatment as indicated for this condition was cantinued. A week later these ulcers and swelling had resolved, but several miliary phlyctenular ulcers were now seen on the inner side of the cornes of the same eye. The treatment was persevered with, and the whole condition of the ayes. vastly improved. A month later the refraction was examined under atropine, when compound hypermetropic extigmatism, was found. Glasses were ordered, and up to the astigmatism, was found. Glasses were ordered, and up to

present her eyes have kept very free from inflammation. some considerable duration; she had intense photophobia and lacrymation; the blepharospasm was so marked that it was with great difficulty that I was.able to inspect the cornea even with retractors, and a nurse to hold the child. There was marked injection of the padpabmal and ocular conjunctiva, and an alcer on each cornea ; she was treated without effect by ordinary measures for three weeks as an out-patient, then for the next month she became an in-patient, where the treatthe next month she became an in-patient, where the treata most beneflcial effect in reducing the conjunctivitis and the a most beneflcial effect in reducing!the conjunctivitis and the healed also. Then she was discharged, wearing dark glasses, owing to there still being some photophobia. Three weeks iater, she.retzrned with the symptoms almost as marked ias in the first instance, andialso a large granulating ulcer on the left cornea. Again out-patient treatment for nearly three weeks made.repy'shight improvement; so she was admitted, but even then the condition, resisted obstinately all our remedies, both local and general ; she was given cod-liver oil, syrup of phosphate of iron, aprup of lodide of iron, and virol, alternately with no benefit; locally, atropine, both in solution and in alntment, was applied, hot and cold bathing, dionine by itself and in combination with the previous drug, but all to no purpose Ginally, adrenalinsalution, was applied, hy, itself; this thrned the scale, and in a fortnight the eyes improved considerably, so that after two months' sojourn in the hospital it was possible to send her to a convalescent home; now she has very little photophobia, no lacrymation, in fact is almost well, but is still using dionine for the corneal nebulae.

Ophthalmia Neanatorum.

This is a purulent type of conjunctivitis found in the newborn, in whlch the conjunctiva shows a marked

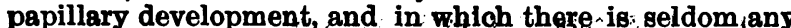
signs of scarring on recovery. The cause of this complaint in the great majority of instances is that micrococcus described by Nelsser in 1879, and known as the Diplococcus gonorrhoeae; il is easlly stained with methylene blue, and is decolorized by Gram's method. This micrococcus is unique in being able to penetrate intact epithelium, hence the importance of early and careful treatment. The other micro-organisms concerned are the pneumococcl, streptococci, Bacterium.coli, and others. The usual mode of infection is that during the birth of the child some vaginal secretion gets into the palpebral sacs, but definite caseg of ante partum infection, have been reported at times, and recently by. Sidney Stephenson and Rosa Ford ${ }^{6}$ and by G. D. Robinson, ${ }^{6}$ in some of whlch apparently the infection took place through intact membranes.

The symptoms commence in the second or third day, varely on the fourth: the lids become swollen, and, may be markedly oedematous, there is inflammation of both palpebral and scleral conjunctiva, usually some chemosis, but not, as a rule; marked; there is free purulent discharge. On examining a case one usually notices the swollen lids glued together by a yellowish dried discharge adhering to them; on senarating them a quantity of the discharge wells up from the palpebral eacs, the cornea is elear at first, but in untreated cases it is soon attacked. The treatment consists in the moin in cleansing the palpebral sacs, and keeping them free from collections of the discharge. A useful lotion to use is 1 in 5.000 mercury perchloride, bat it must be noted that one does not depend on the antiseptic properties of the lotion 89 much as on the mechanical effect of continually irrigating the eyes; this should be done every hour, or two at the least; then every day one performs savonnage with 2 per cent. silver nitrate. In this complaint prophylaxis is of the utmost importance. The majority of pregnant women have a vaginal catarrh, so antlseptic injections immediately before parturition form the first step' then after the child is born the closed lids are wiped with a clean rag, and then after its first bath the eyes are carefully cleansed with boracic lotion, and then a drop of 2 per cent. silver nitrate solution is dropped on to each eye; this is the method advocated. byj Credé, who reduced the percentage of cases in Leipsig Lying-in Asglwm. from 10.8 to 0.1 or 0.2 .

N. F., aged 14 days, was brought to haspital, onaccount of a cold in her eyes, which did not get / well. Thers was free purulent discharge; the lids were not. muph swollen; both. palpebral and ocular conjunctiva was markedly injected. In the right eye the cornea was clear, but in the left vhere was a lange wentral uloer on the cornea, which had perforsted, and thes eye. wa already lost, boing in a candition of panophthalmitis. The eyes were treated as indicated above, and now the conjunctivitis has quite resolved. The right eye is quite clear and well, but the left eye, although the conjunctivitis bas resolved, is in a state of phthisis bulbi and is rapidly shrinking, there being|very little sign of the cornes left.

1 Parsons, The Pathology of the Eye, vol i. 2 Darier, Lecons de therapeutique oculaire, second edition. 3 Leber, Wintersteiner, Beriaht der ophthalmologische Gesellschoft zu Heidelberg. 1901. 4 V. Michel, Zeitschrift Ophthalmoscope, April, '1906. 6 G. D. Robinson, Ophthalmoscope, June, 1907.

\section{A CRITICAL STUDY OF ORGANIC PREPARA- TIONS OF SILVER IN THE TREATMENT OF CONJUNCTIVITIS.}

BY JOHN MUIR KELLY, M.D.GLASG., CLINICAL ASSISTANT, GLASGOW EXE INFIRMARY. (From Dr. Fergus's Clinic and the Pathological Laboratory of the

SINGE the introduction of argyrol and protargol there has been among clinical observers a great difference of opinion regarding their efficacy in disfas es of the conjunctiva. Many have degcribed them as being superlor to silver nitrate; but others, like Dr. Pooley of New York, have regarded them as "bland, harmless, and inefficient." 1

During the past year a serles of experiments have been performed with these preparations and with silver nitrate to ascertain their relative bactericidal powers. One reallzes that in a laboratory it is impossible to reproduce exactly the conditions found in Nature; but as the same methods were used with each substance the results have at least a comparative value. The organism used was Staphylocoocus pyogenes aureus, because it was easy to identify and because it gave results that were remarkable for their consistency. A small number of experiments were performed with the Streptococeus pyogenes brevis, the pneumococcus, and the gonococcus, but the results obtained were not nearly so consistent as those obtained with the Scaphylocoecus pyogenes aureus.

Quantities of argyrol and protargol were bought from a wholesale chemist and were submitted to a gravimetric analysis. The percentage of silver was ascertained by incinerating the substance, heating with nitric acid, dissolving in water, and then precipitating the silver with hydrochloric acid and weighing the precipitate. As a nesult of two estimations with each preparation, it was found that argyrol contained 17,01 per cent..and protargol 7:03 percent. of ssilver. These, figurearare to be compared with 68,6 persent. of silven.present in sllyer nitrate. The manufecturens state that these mrepaxations, deteriorate when kept long in solution. We had noticed that bottles in which the solutions had been kept for some weeks gradually acquired a coating of silver oxide. To avoid any errors from faulty solution or from deterioration the solutions were carefully made according to the methods desertbed by the manufacturers; were kept in dark glase bottles, and were always used before the third day.

An emulsion was made of a three dayg' growth on agaragar of Staphylosoccus pyogenes aureus, and was then flltered 